\title{
Alternative source of probiotics for lactose intolerance and vegan individuals: sugary kefir
}

\author{
Murat AÇIK ${ }^{1 *}$ (D), Funda Pınar ÇAKIROĞLU1 ${ }^{1}$, Murat ALTAN ${ }^{1}$, Tuğçe BAYBO ${ }^{1}$
}

\begin{abstract}
In this review, we aimed to explain general information about sugary kefir, microbial diversity, production process and potential health effects. Although sugary kefir has been known for many years, it has not been studied much. Studies have shown that sugary kefir has a similar microbial diversity compared to traditional milk kefir and therefore may be an alternative source of probiotics. However, sugary kefir has been shown to contain probiotic properties such as adhesion to the mucosa by reaching the lumen of the mucosa, colonization of the pathogens to the mucosa. In this way, potential health effects such as antimicrobial activity, suppression of inflammation agents, reduction of oxidative stress, immunomodulation, anticancer, and anti-obesity have been demonstrated by clinical studies. However, studies on whether or not these effects are present on humans are very limited. Therefore, randomized double blind placebo controlled studies are needed to investigate potential health effects on humans.
\end{abstract}

Keywords: kefir; sugary kefir; probiotics; microorganisms; health benefits.

Practical Application: The term probiotic is used to describe bacteria, which mean for life and usually. However, since the incidence of lactose intolerance and the number of vegan individuals have increased in recent years, interest in alternative probiotic sources that these individuals may consume has increased. One of these is the sugary kefir beverage, an alternative to the traditional milk kefir. Sugary kefir has been shown to contain probiotic properties such as adhesion to the mucosa by reaching the lumen of the mucosa, colonization of the pathogens to the mucosa. Sugary kefir could also be an alternative source of probiotics for individuals who cannot consume dairy products.

\section{Introduction}

Functional foods affect biological functions in the human body, improve health status and reduce the risk of disease development. This category also includes fermented products containing probiotic microorganisms, defined as "live microorganisms that, when administered in adequate amounts, confer a health benefit on the host"(Hill et al., 2014). The interest in probiotics in the scientific world has increased significantly since the beginning of the twenty-first century, regarding their roles on intestinal microbiota, health, and disease. Today, probiotics are available in different forms (encapsulated, tablet, envelope, vial, food, supplement, milk formulas, etc.) as functional food supplements and medicines in the market (Saarela, 2018). In addition, with the use of kefir microencapsulation technology in recent years, the microencapsulation of kefir by spray-drying is recommended to give a standard and more stable product with instant properties (Nale et al., 2018).

Undoubtedly, dairy products contain the most valuable nutrients in the world. For example, milk is the richest source of calcium in the world. Moreover, since the positive effects of milk on health are known, the majority of studies belong to the past (Kalicka et al., 2019; Soares et al., 2019; Tomar, 2019). Yogurt and kefir are undoubtedly the most known and consumed fermented dairy products in the world (Yildiz, 2016). Kefir is a viscous, light-carbonated milk beverage that contains a small amount of alcohol (less than $2 \%$ by volume) and is believed to be originated from the Caucasus mountains like yogurt. According to the Turkish
Food Codex, kefir is a fermented milk product produced using specific strains of Lactobacillus, Leuconostoc, Lactococcus and Acetobacter and cultures that may contain lactose-fermenting (K. marxianus) and -non-fermenting (S. unisporus, S. cerevisiae, and S. exiguus) yeasts or kefir grains (Yönetmeliği, 2002). Kefir is usually obtained by fermenting cow's milk (Chen et al., 2018). However, it has been emphasized that kefir can be produced from milk of different animals in addition to traditional cow milk. However, Gul et al. (2018) repoted that the buffalo milk kefir samples had better sensory characteristics than the cows' milk kefir samples, except for texture scores. Therefore, buffalo milk should be used for industrial kefir production due to its lower serum separation, which is a problem for kefir during storage. Demirci et al. (2019) investigated that kefir was used as substitute for yoghurt in tarhana production partially and completely to investigate the effects on fermentation activity, nutritional, sensory and rheological properties of tarhana. As a result, it was found that kefir represents another important fermented milk product offering a good alternative in tarhana fermentation. In addition, Silva et al. (2018a) suggested that soymilk Kefir-based functional beverage, an innovative product and great sensory characteristics, using both kefir and soymilk, for technological use in the food industry. Kefir has antimicrobial effect on many Gram positive and Gram negative bacteria and yeast. In vitro tests with kefir cell free extracts, the growth of Staphylococcus aureus, Bacillus cereus, Escherichia coli, Clostridium tyrobutyricum and Listeria monocytogenes was inhibited (Kim et al., 2016; 
Kıvanç \& Yapıc1, 2015). In general, the antimicrobial activity of kefir is caused by bacteriocin-like substances such as lactic acid, lactic acid, hydrogen peroxide, carbon dioxide, diacetyl, acetaldehyde and/or bacteriocin produced by LAB. However, the production and storage conditions need to be paid attention to. Because, bacteria such as E. coli and S. aureus have a high risk of contamination in the production process. Especially if $E$. coli contamination is assumed to be at low concentration, kefir is a safe fermentation drink (Kıvanç \& Yapıc1, 2018). The sharp acid and yeasty flavour, together with the prickly sensation contributed by the carbon dioxide produced by the yeast flora can be considered as the typical kefir flavour. The microorganisms present in the kefir grains, the chemical attributes of the milk employed, and the manufacturing technology are all factors that influence the physicochemical and sensory characteristics of kefir during the storage. In addition, it was demonstrated that positive effects on sensory profile have been achieved by adding flavor enhancers instead of reducing some elements such as sodium in the content of probiotic foods in recent years (Silva et al., 2018b). After the twentieth century, it has become a very popular beverage because the studies have shown that it has many beneficial effects on health (Randazzo et al., 2016).

Over the centuries, lactic acid fermentation has been used as a method to maintain, improve or modify the flavor of dairy products. Milk fermentation is carried out by lactic acid bacteria (LAB) such as Lactobacillus, Lactococcus, Leuconostoc, Pediococcus, and Streptococcus. Most of the kefir studies have focused on milk substrates derived from cow's, sheep's, goat's or other types of milk. However, there is a restricted consumption of milk kefir for vegans, individuals with lactose intolerance and consumers with allergies to dairy products. Therefore, the alternative way to obtain the beneficial effects of kefir is to use non-dairy-containing substrates in kefir production (Fiorda et al., 2017). Kefir grains can also be grown in a crude sugar and water solution known as sugary kefir (da CP Miguel et al., 2011). Therefore, another fermented beverage has recently been produced, whose fermentation is induced by different types of grains and which uses fruit as a substrate (usually fig and lemon) or sucrose solution. It is called as sugary kefir, also known as water kefir in the literature and the grains that perform such fermentation are also called sugary kefir grains (Hsieh et al., 2012). The grains of sugary kefir are defined as dextran-containing biomasses, which are $\alpha$-6-linked glucose polymers (Gulitz et al., 2011). It is a homemade fermented beverage produced by fermenting the sucrose solution with kefir grains with dried and fresh fruit and mostly consumed in Mexico and Brazil (da CP Miguel et al., 2011). It is also called "Ginger Beer", "Tibi Grains", "Californian Bees" "African Bees", "Beer Nut", "Balm of Gilead". In this study, it was aimed to introduce sugary kefir produced as an alternative to kefir containing dairy products and to evaluate its effects by comparing it to milk kefir.

\section{Sugary kefir: definition, origin and distribution}

Sugary kefir, also known as water kefir in the literature, is milk-free kefir prepared with fruit extracts fermented by kefir grains composed of Xeromyces, Candida, Saccharomyces, and $\mathrm{LAB}$, or with a non-fruity sucrose solution (Randazzo et al.,
2016). Sugary kefir fermentation is carried out with yeasts, $\mathrm{LAB}$ and acetic acid bacteria (AAB) consortium (Fiorda et al., 2017). Kefir grains that ferment brown sugar are yellowish, clear and crystalized different from the appearance of the milk kefir grains (Chen et al., 2018). Sugary kefir grains are small translucent mucinous masses consisting of a polysaccharide gel containing LAB and yeasts. It is a heteropolysaccharide complex and consists of dextran. The first scientific explanation of sugary kefir was published in the 19th century as the Mexican-origin "Tibi", which is associated with the Opuntia and whose granules are called as "ginger beer" (Hsieh et al., 2012). Kefir grains processed in a sugar solution are known as "tibico" or "tibi". These tibico grains are very similar to milk kefir grains in terms of their microbiological structure (da CP Miguel et al., 2011). However, the composition, frequency, and concentration of microbial species vary according to the carbon and energy sources in the environment for grain fermentation (Fiorda et al., 2017). Tibico is mainly consumed in Mexico and Brazil. Microbial populations of Tibico grains include AAB such as Lactobacillus, Leuconostoc, Streptococcus, Acetobacter, and yeasts such as Saccharomyces, Zygosaccharomyces, Candida, and Kloeckera (da CP Miguel et al., 2011). These microorganisms are embedded in a flexible, water-soluble branched glycogalactant matrix called kefiran (Randazzo et al., 2016). Kefir grains are generally present in a sugar solution of 3-10\% (da CP Miguel et al., 2011). This beverage, which is intensely consumed in the United States, Japan, France, and Brazil, is considered among functional foods. In the literature, sugary kefir is shown to have a microbial relationship with $\mathrm{LAB}$ and yeast species similar to traditional milk kefir fermentation. In the studies, adaptation status of kefir grains in non-dairy substrates such as fruit, vegetables, and molasses was tested for the production of functional beverages with different sensory characteristics. The result is a creamy beverage with natural carbonate, which has an acidic taste due to the metabolism of yeasts and $\mathrm{LAB}$ (Fiorda et al., 2017).

In a study, the microbiological, chemical and sensory characteristics of kefir-like beverages formed after fermentation of fruit juices obtained from fruits grown in Sicily (Southern Italy) with kefir microorganisms were examined. The results revealed that both $\mathrm{LAB}$ and yeasts were able to grow in all fruit juices tested, but the highest levels were recorded in prickly pear fruit juice. As lactic acid content was determined in kefir-like beverages obtained, all fruit juices were subjected to a lactic fermentation to obtain sugary kefir (Randazzo et al., 2016). In another study using sugary kefir microorganisms, carrot, fennel, melon, onion, tomato and strawberry juices were used as substrates and it was shown that LAB and yeasts could grow in these juices. After fermentation, it was observed that the soluble solids content decreased, and the number of volatile organic compounds increased. It was decided that carrot kefir-like beverage would be more preferred as a result of an overall quality assessment. These findings support the need for further development of kefir-like beverages which have additional benefits and functional characteristics (Corona et al., 2016). 


\section{Production of sugary kefir beverage}

Sugary kefir is a traditional homemade beverage and consumed in many countries around the world. In the production of sugary kefir, the product (brown sugar) is pasteurized after being homogenized with water. The pasteurized product is cooled and is mixed with kefir grains and left to fermentation at $25-30^{\circ} \mathrm{C}$ for approximately 24 hours. Then, kefir obtained is separated from its grains by filtration and packaged. It is delivered to the end consumer without breaking the cold chain in the storage and transportation processes (Figure 1) (Guzel-Seydim et al., 2011).

Due to the positive effects of kefir on human health, studies are carried out to use many foodstuffs other than dairy products as substrates during fermentation. Most of these are fruits, simple sugars, and vegetables. Traditionally, in the process of preparing sugary kefir from different fruits, kefir grains are added in a solution containing $8 \%$ sucrose, fresh or dried fruits (typically figs) and lemon slices. As a result of fermentation in one or two days at room temperature, acidic, carbonated and straw-colored sugary kefir with low sugar and alcohol is obtained (Gulitz et al., 2011). So far, several recipes have been developed in the production of sugary kefir with the help of different products. For example, pineapple, brown sugar, cinnamon, and kefir grains are used in the production of "Tapache" and this beverage is very popular in Latin American countries. Grape-based kefir beverage called "Kefir d'uva" is a very popular drink in Italy (Gaware et al., 2011).

Some foods such as carrot, tomato, ginger or fennel are also used for making kefir. The ginger-based kefir, called ginger beer, is now consumed mostly by people living in the rural areas of Greece. In addition, kefir grains are fermented much slower in ginger than brown sugar and consequently, offer higher ethyl alcohol content (Ward, 1891). Ginger beer is also consumed in East African countries besides Greece and called "Tangawizi” in these countries.
Another group of foods used in the production of kefir is simple sugar products and cereals. They can be easily obtained and are widespread in Latin countries. In making sugary kefir, cereals are used to improve the organoleptic properties and nutritional quality, and to enable the production of new fermented beverages by providing a controlled fusion of LAB and yeasts to provide a low alcohol content. During fermentation, the size of kefir grain increases, it is divided, and more cells are immobilized. If the culture conditions are appropriate, regular fermentation takes place over a long period of time (Pidoux, 1989). In the first study for the production of rice flakes-based kefir, Magalhães-Guedes et al. (Magalhães-Guedes et al., 2018) reported that the amount of kefiran (polysaccharide) released during fermentation depends on the microorganisms, culture medium composition, temperature and fermentation time. It was stated that the growth of microorganisms in the environment is related to the presence of nutrients in rice extract. In 24 hours, it was observed that $\mathrm{pH}$ value decreased (4.3-3.5) and acidity increased $(\sim 0.2)$. These observations reveal that the fermentation process takes place upon acid production and that the sugary kefir grains are able to ferment rice extract. It is stated that LAB is responsible for low $\mathrm{pH}(\sim 3.5)$ and high acidity $(\sim 0.3)$ found at the end of fermentation. The results show that yeasts such as Saccharomyces, Kluyveromyces, Lachancea, and Kazachstania as well as Lactobacillus, Lactococcus and Acetobacter are microorganisms found in sugary kefir grains and rice cereal-based kefir.

\section{Microbial diversity in sugar kefir: differences from milk kefir}

Sugary kefir is a fermented beverage obtained by the addition of sugary kefir grains that act as inoculum to a mixture of different substrates instead of water, sucrose or sugar (Laureys \& De Vuyst, 2014). Traditional milk kefir is obtained with the fermentation of milk using kefir grains; in industrial kefir production, with

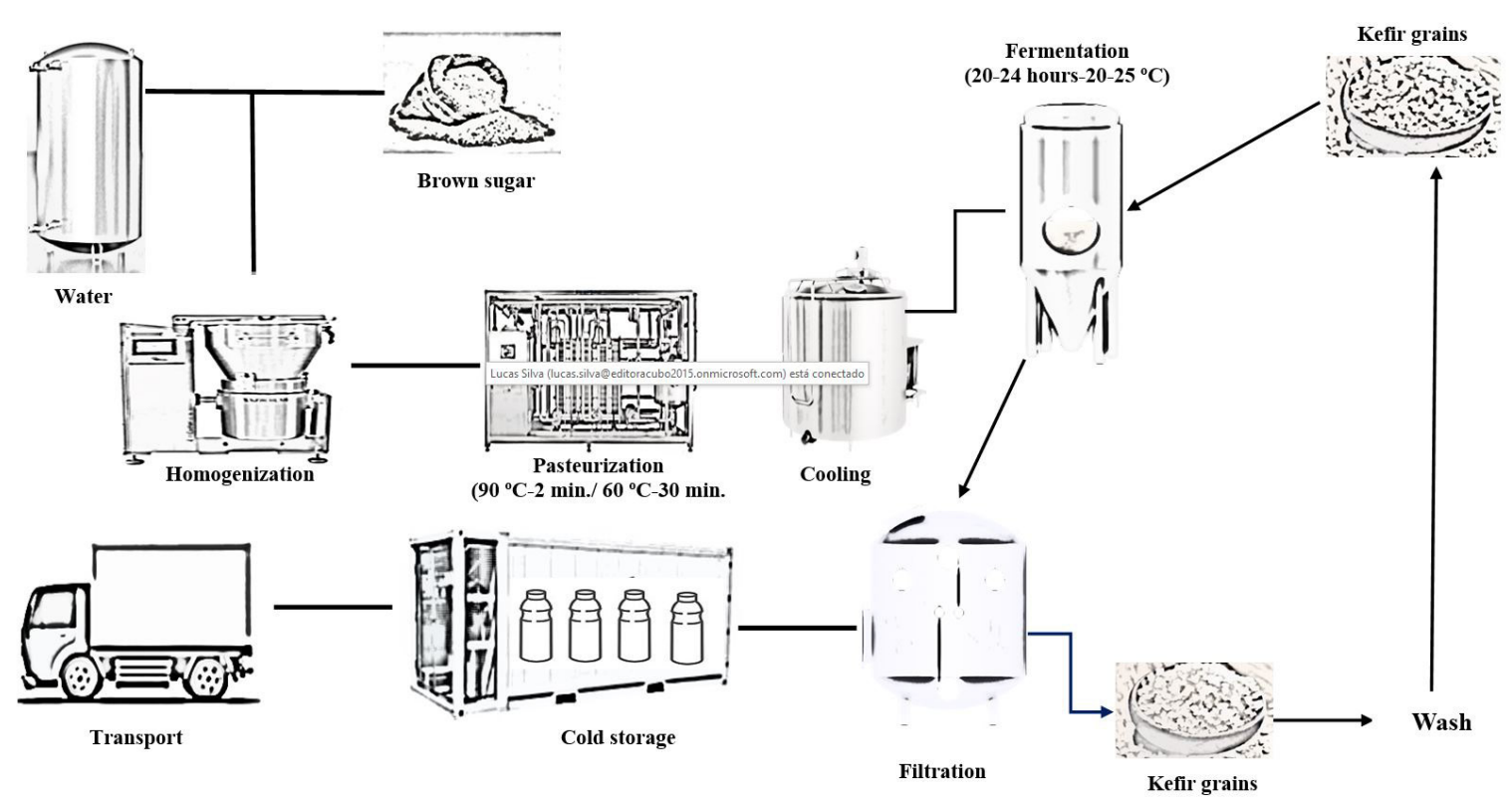

Figure 1. Production flow of sugary kefir. 
culture microorganisms obtained from grains. Sugary kefir grains and milk kefir grains are similar in terms of structural and microorganism contents. However, different types of carbon structure or components, which are the energy source of the substrates, can be effective in microbial growth (Tomar et al., 2017). Microbial differences between milk and sugar kefir were shown in Table 1. In countries where sugary kefir is consumed more like Brazil, Belgium, Germany, Taiwan, and Argentina, there have been studies for the microbial characteristics of kefir for the last 30 years (Blaiotta et al., 2014; Davidovic et al., 2015; Marsh et al., 2013; Alsayadi et al., 2012).

The largest data on the microbial consortium of sugary kefir were reported by Gulitz et al. (Gulitz et al., 2013). The $16 \mathrm{~S}$ rDNA amplicon sequence was used to determine the microbial composition. The most striking part of this study is the detection of Bifidobacterium species for the first time, unlike the previous identification studies. In another study, Laureys et al. (Laureys et al., 2016) uncovered several unspecified species like Bifidobacterium (B. psychra-erophilum/crudilactis) and a new species (B. aquikefiri $s p$ ) in homemade kefirs in Belgium.

Substrates with high sucrose content stimulate the reproduction of Saccharomyces species. Since there are invertase enzyme systems which can provide hydrolysis of sucrose and fructose in this yeast species, it results in an accelerated reproduction using glucose, a free metabolite (Sikander, 2007). In addition, other yeast species such as Hanseniaspora, Pichia and Lachance with high fermentative capacity are also found in sugary kefir. These yeast species are more dominant in the first stage of fermentation and when the process is completed, it is replaced with S. cerevisiae (Morrissey, Davenport, Querol, \& Dobson,
2004). The presence of such yeasts in sugary kefir contributes to the improvement of the sensory quality of probiotic beverages and provides a potent and typical yeast aroma and a refreshing and pungent flavor (Magalhaes et al., 2010).

In the study conducted on Brazilian kefir by Zanirati et al. (2015) LAB of eight kefir grains, which were reproduced in milk or sugar solutions from five different regions in Brazil, were isolated and Lactobacillus isolates were selected based on the desired probiotic properties in vitro conditions. In the study, it was observed that sugary water kefir grains exhibit lower (about one log lower) LAB population levels than milk kefir grains. In another study depicting the microbial population of sugary kefir grains by an electron microscope, it was determined that yeasts and bacteria were formed in a variety of forms, creating a complex biofilm on the grain surfaces embedded in the dextran matrix. Polymer production was carried out by Lactobacillus. In this study, it was determined that the population in sugary kefir grains were different from the one in milk kefir grains. While sugary kefir grains contain high amounts of bacterium cocci, they are reported to be less in milk kefir grains. C. kefyr and $S$. turicensis yeast species are reported to be common in two types of kefir (Hsieh et al., 2012).

In the study conducted by Ghazzay (2014) molasses and milk sugar were used as the substrate for the production of kefir. In the study, the fermentation process was carried out at different temperatures $\left(25,30,35\right.$ and $\left.40{ }^{\circ} \mathrm{C}\right)$ for sugary kefir. The suspension was kept in the refrigerator to measure the acid and sugar concentration. The fermentation of sugary kefir was carried out with acid production. The sugary kefir samples showed increased acidity at $35{ }^{\circ} \mathrm{C}$ and decreased acidity at

Table 1. Microorgchartanisms obtained in sugary and milk kefir grains.

\begin{tabular}{|c|c|c|c|}
\hline Microbial group & Species & Sugary kefir & Milk kefir \\
\hline \multirow[t]{7}{*}{ Bacteria } & Acetobacter & A. fabarium, A. orientalis, A. lovaniensis. & $\begin{array}{l}\text { A. fabarium, A. orientalis, A. lovaniensis, Acetobacter } \\
\text { aceti, A. rasens. }\end{array}$ \\
\hline & Lactobacillus & $\begin{array}{l}\text { L. brevis, } L . \text { buchneri, } L . \text { casei subsp. casei, } L . \text { casei subsp. } \\
\text { rhamnosus, L. diolivorans, L. fermentum, L. harbinensis, } \\
\text { L. hilgardii, L. hordeii, L. kefiranofaciens, L. kefiri, L. } \\
\text { lactis, L. mali, L. nagelli, L. paracasei, L. parafarraginis, } \\
\text { L. perolens, L. plantarum, L. satsumensis. }\end{array}$ & $\begin{array}{l}\text { L. acidophilus, L. brevis, L. buchneri, L. casei subsp. } \\
\text { pseudoplantarum, L. delbrueckii, L. fermentum, } \\
\text { L. helveticus, L. kefiranofaciens, L. kefiri, L. otakiensis, } \\
\text { L. paracasei, L. parabuchneri, L. plantarum, } \\
\text { L. rhamnosus, L. sake, L. sunkii. }\end{array}$ \\
\hline & Leuconostoc & L. citreum, L. mesenteroides & L. mesenteroides \\
\hline & Lactococcus & & L. cremoris, L. lactis, L. raffinolactis \\
\hline & Pediococcus & & P. acidilactici, $P$. dextrinicus, $P$. pentosaceus \\
\hline & Streptococcus & & S. durans, S. thermophilu. \\
\hline & Diğer türler & $\begin{array}{l}\text { Lysinibacillus sphaericus, Oenococcus kitaharae, } \\
\text { Bifidobacterium psychraerophilum. }\end{array}$ & \\
\hline \multirow[t]{8}{*}{ Yeast } & Candida & & $\begin{array}{l}\text { C. iconspicua, C. kefir, C. krusei, C. lambica, C. maris, } \\
\text { C. humilis }\end{array}$ \\
\hline & Saccharomyces & S. cerevisiae & S. cerevisiae, S. turicensis \\
\hline & Pichia & P. membranifaciens, P. kudriavzevii & P. fermentans. \\
\hline & Lanchancea & L. fermentati, L. meyercii & L. meyercii. \\
\hline & Kluyveromyces & K. lactis, K. marxianus & K. lactis \\
\hline & Kazachstania & K. aerobia, K. unispora & K. unispora, K. servazzii, K. aerobia, K. solicola. \\
\hline & Hanseniaspora & H. valbyensis, H. uvarum & H. guillermondi. \\
\hline & Other species & $\begin{array}{l}\text { Zygotorulaspora florentina, Issatchenkia orientalis, } \\
\text { Zygosaccharomyces fermentati, Dekkera bruxellensis }\end{array}$ & $\begin{array}{l}\text { Cryptococcus humicolus, Geotrichum candidium, } \\
\text { Zygosaccharomyces fermentati }\end{array}$ \\
\hline
\end{tabular}


$25^{\circ} \mathrm{C}$. Furthermore, the kefir samples showed the highest sugar consumption at $35{ }^{\circ} \mathrm{C}$ and the lowest sugar consumption at $30{ }^{\circ} \mathrm{C}$. As the temperature increased (up to $35^{\circ} \mathrm{C}$ maximum), the acidity of the fermentation solution increased and the fermentation stopped at $40^{\circ} \mathrm{C}$. Similar results were reported for yogurt samples fermented at $37^{\circ} \mathrm{C}, 40^{\circ} \mathrm{C}$ and $46^{\circ} \mathrm{C}$.

In the study conducted by Hsieh et al. (2012), sugary kefir grains and brown sugar were fermented cow's milk or goat's milk. By using culture-dependent and culture-independent methods, microorganisms found in both grains and filtrate were identified and their distribution was then evaluated. The structure of the grains was observed by scanning with an electron microscope. For the identification results, three LAB species (L. mesenteroides, $L$. mali and $L$. hordei) were found in the grains fermented with brown sugar when sugar and milk were compared in terms of fermentation medium. However, L. mesenteroids, L. lactis, B. psychraerophilum and E. faecalis were detected in the grains fermented using cow's or goat's milk. This study is critical for understanding the mechanism of kefir formation and growth because the main aim was to examine the relationship between fermentation medium and kefir microorganisms.

It was concluded that sugary kefir grains are very similar to milk kefir grains in terms of their structure, microorganisms in fermentation and the products formed during the fermentation process (da CP Miguel et al., 2011). The size and structure of kefir grains are significantly affected by the culture medium. The distribution of strains may vary depending on the carbon and energy sources present in the environment for fermentation and these microbial changes appear to further affect the granulation and growth of the grains (Hsieh et al., 2012).

\section{Potential health effects of sugary kefir}

Apart from creating a functional new product, another important reason for fermenting foods is to direct microorganisms to produce bioactive substances and enzymes that are very beneficial to health. Fermented foods and beverages include both functional and non-functional microorganisms (Tamang et al., 2016).

Kefir is a refreshing fermented product with strong sensory characteristics due to lactic acid, acetaldehyde, acetoin, ethanol, and other by-products and it is obtained from the variety of microorganisms found in kefir grains during fermentation (Esmek \& Güzeler, 2015). In times when modern medical therapies were not available, it was used for the treatment of tuberculosis, cancer and gastrointestinal diseases and was also associated with long life in the Caucasus, where it was born (Randazzo et al., 2016). There are many studies in the literature proving that kefir, a probiotic product, is bioactive (Ghazzay, 2014). In the literature, while sugary kefir has been shown to be useful as an alternative probiotic source in vegans or individuals with lactose intolerance, scientific evidence is still insufficient in studies. Sugary kefir, which has a wide range of microorganisms, has been proved to have probiotic characteristics such as adhesion to the mucosa by reaching to intestinal lumen, colonization, and blocking of the pathogens to the mucosa (Golowczyc et al., 2011; Magalhaes et al., 2010; Soccol et al., 2010).

\section{Antimicrobial}

Kefir and kefir grains can be antagonistic to many microorganisms in the gastrointestinal tract. Kefir inhibits the attachment of pathogens to the intestinal mucosa, but also inhibits the growth of pathogen by acid and bacteriocin production (Rosa et al., 2017; Tomar et al., 2017). It has been found in the studies that kefir has antimicrobial characteristics against many pathogenic microorganisms such as $S$. aureus, $P$. aeruginosa, S. typhimurium, E. coli and L. monocytogenes (Huseini et al., 2012; Leite et al., 2015; Zanirati et al., 2015).

Rodrigues et al. (2005) investigated the antimicrobial and curative effect of kefir and kefiran obtained from sugar cane. With the help of disc diffusion method, kefir and kefiran were found to show antimicrobial activity against high-resistance pathogenic strains such as S. pyogenes ATCC 17568, P. aeruginosa, ATCC 27853, C. albicans ATCC 10232, S. typhimurium ATCC 14028, L. monocytogenes ATCC 4957 and E. coli ATCC 8739. In addition, $S$. aureus inoculated rats with skin lesions showed improvement in wounds after 7 days of kefir gel administration.

Puerari et al. (2012) examined the microbial and chemical composition of kefir by adding sugary kefir grains to the cocoa pulp solution. The chemical composition of kefir was examined, and it was observed that it was rich in the contents of propionic, citric, and malic acids. These compounds are known to show an antimicrobial effect against the pathogenic bacteria by increasing the acidity of the medium (Nualkaekul \& Charalampopoulos, 2011). In addition, due to the fact that the LAB is the most detected type in the stable microbiota of kefir, the low acidity value of the kefir $(\mathrm{pH}=4.5)$ and the high antimicrobial activity of kefiran may prevent the development of pathogenic microorganisms.

Kefir can be used as a therapeutic agent in diarrhea and ulcer due to its antimicrobial activity against foodborne pathogens such as L. monocytogenes and Y. enterocolitica and against $H$. pylori. The bacteriocin, $\mathrm{H}_{2} \mathrm{O}_{2}$ and organic acids in kefir provide a protective effect by killing these pathogenic organisms. Silva et al. (2009) investigated the antimicrobial activity of kefir grains obtained from different types and concentrations of sugary kefir against pathogenic organisms causing gastrointestinal disorders and oral candidiasis. According to the results of the study, it was observed that kefir grains obtained at the end of fermentation of brown sugar significantly inhibited the reproductive activity of C. albicans after 144 hours. Kefir grains obtained from brown sugar support antimicrobial activity by producing inhibition halos corresponding to $35,14,12,14$ and $14 \mathrm{~mm}$ for C. albicans, S. typhi, S. sonnei, S. aureus and E. coli, respectively.

\section{Antioxidant effect}

Antioxidants are substances that eliminate the negative effects of free radicals and prevent damage to cells. They are examined in two groups as endogenous and exogenous antioxidants (Karabulut \& Gülay, 2016). Endogenous antioxidants are classified as enzymatic or non-enzymatic antioxidants. Enzymatic endogenous antioxidants are superoxide dismutase, catalase, peroxiredoxins, glutathione peroxidase, and glutathione reductase. Ceruloplasmin, ferritin, albumin, metallothionine, and transferrin are examples of non-enzymatic endogenous 
antioxidants. Exogenous antioxidants are found in fruit, vegetables, some beverages, nuts, and cereals in significant amounts (Mironczuk-Chodakowska et al., 2018). The health benefits of fruits contained in sugary kefir are related to their ability to contain different compounds with antioxidant characteristics and ability to neutralize the activity of free radicals. The fruits have antioxidantive compounds such as superoxide dismutase, catalase, peroxidase, phenolic acids (catechins, flavonols, anthocyanins etc.) and vitamins A, C, E (Ariza et al., 2015). In a study, soybean was used as a substrate in the production of kefir and antioxidant characteristics were investigated. It was determined that the samples used as soybeans had higher antioxidant capacity than colostrum and cow milk. The antioxidant characteristics of soybean are linked to the high levels of flavonoids, namely genistein and daidzein in soybeans (Fiorda et al., 2016).

Oxidative processes damage the proteins, lipids and other cellular components that are necessary to preserve the health and appearance of the skin and cause skin changes (Leroi \& Pidoux, 1993). Regular kefir intake has a protective effect against the negative effects of aging (Gaware et al., 2011). In the study conducted by Alsayadi et al. (2012) the antioxidant activities of the sugary kefir samples were measured in terms of the ability to hydrogenate or to clean radicals using stable radical 1,1-diphenyl-2-picrylhydrazyl (DPPH). The results revealed that sugary kefir had good antioxidant activity. Oxidative stress plays an important role in the development of chronic diseases such as cardiovascular diseases, diabetes, cancer and rheumatoid arthritis (Mironczuk-Chodakowska et al., 2018). It has been concluded that sugary kefir may be a natural source of antioxidants that prevent oxidative stress in health development (Muneer Alsayadi et al., 2012).

\section{Anticancerous activity}

The anticancerous activity role of kefir is generally in the form of cancer prevention and suppression of tumors at an early stage. Such a role is achieved by delaying enzyme activities of carcinogens with carcinogenic-inhibiting compounds or by activation of the immune system (Sharifi et al., 2017).

Kefir reduces the level of malondialdehyde that is involved in the formation of oxidative stress and increases the level of glutathione peroxidase enzyme and provides an antioxidantive effect. On the other hand, kefir can bind to DPPH and superoxide radicals and inhibit linoleic acid peroxidation. Alsayadi et al. (2012), found that sugary kefir neutralized 9.8-63.1\% of DPPH and inhibited ascorbate oxidation by $6.0-25.5 \%$. Thus, sugary kefir has an anticarcinogenic effect by reducing the level of free radicals in the medium and alleviating the load of antioxidant enzyme systems.

Conjugated linoleic acid isomers, which are highly present in sugary kefir, can reduce the mutagenic effect of butyric, palmitic, palmitoleic and oleic acid methyl methanesulfonate, sodium azide and aflatoxin B1. It can also show a protective effect on radiation-exposed cells (Guzel-Seydim et al., 2011; Teruya et al., 2013).

Kefir is, in fact, a unique culture product with anti-inflammatory, immunomodulatory and anticancer effects due to its probiotic properties. However, kefir may produce different effects in different parts of the world because it is produced with different production techniques (de LeBlanc et al., 2006; Vinderola et al., 2005). In a study, antimetastatic and antiangiogenic effects of sugary kefir were examined in $4 \mathrm{~T} 1$ breast cancer cells. In vitro conditions, 4T1 cancer cells were treated to observe the effect of anti-migration and anti-invasion of kefir water. In addition, rats with $4 \mathrm{~T} 1$ cancer cells were given orally kefir water for 28 days. A significant reduction was found in tumor weight and volume in the kefir-treated group compared to the control group. The rate of lung and bone marrow metastases in kefir-treated rats was lower than in the control group. Moreover, the cytokines involved in tumor formation (IL (Interleukin)-10 and IL-1 $\beta$ ) and immunomodulatory cytokines (IFN (Interferon)-immün and IL-2) were found to be lower in rats receiving kefir water than in the control group (Zamberi et al., 2016).

In many studies, the use of milk kefir has shown promising results on breast, colorectal and lung cancer and malignant T lymphocytes thanks to its anti-tumor, anti-proliferative and apoptosis inducing characteristics in both in vivo and in vitro studies (Maalouf et al., 2011; Topuz et al., 2008). However, studies investigating the effectiveness of sugary kefir on cancer are rather limited. It is important to reveal anti-cancer characteristics of sugary kefir by conducting cellular and molecular studies to make sure whether it can be used as a therapeutic agent in the future.

\section{Obesity and metabolic syndrome}

Obesity is a chronic disease caused by the imbalance between energy intake and energy consumption and results in an increase in the proportion of body fat mass to lean body mass (Altunkaynak \& Özbek, 2006). Animal and human studies have shown that intestinal microbiota consisting of trillions of bacteria is associated with energy homeostasis (Borgeraas et al., 2018). Increased levels of lipopolysaccharide in obesity cause low-grade inflammation that can lead to metabolic complications of diabetes and obesity in tissues and organs. The mechanisms underlying some metabolic diseases are thought to be associated with changes caused by a host in the intestinal microbiota pattern. Many studies have shown that the host may positively alter the intestinal microbiota due to prebiotic nutrients (Kim et al., 2015).

Microbial communities isolated from sugary kefir grains are thought to have probiotic characteristics. In a study, eight LAB strains were isolated from sugary kefir grains. The L. rhamnosus $G G$ strain was used as a reference probiotic strain and was found to have anti-diabetic characteristics. A diet supplemented with L. mali APS1 isolated from sugary kefir grains was found to be effective in maintaining blood glucose levels in obese rats (Koh et al., 2018). Other probiotic microorganisms such as L. casei, L. acidophilus, and B. longum have also been reported to have hypocholesterolemic effects (Kerry et al., 2018). There is increasing evidence that kefir may be a promising agent in reducing the risk of many diseases, including high glucose levels, obesity, hypertension, high triglycerides, and metabolic syndrome characterized by low levels of high-density lipoprotein cholesterol. Studies have shown that IL-1 disrupts peripheral insulin sensitivity and a high concentration of IL-1ß, which correlates with MetS, have been found in individuals with diabetes. 
Moreover, it was observed that obese subjects who consumed kefir had lower IL-1 levels and lower waist circumference values (Rosa et al., 2016).

\section{Results and discussion}

In conclusion, it has been shown in many studies that kefir increases the anti-inflammatory and antioxidant activity in metabolism and has positive effects on gut microbiota thanks to the probiotics it contains. Kefir is traditionally produced by fermenting milk and dairy products, and the use of milk as a substrate limits the consumption of some individuals. In this context, the production of new probiotic products that do not contain milk is important in terms of providing consumption opportunity in many situations such as lactose intolerance, milk allergy, vegetarianism, and veganism. Therefore, many processes such as design and testing of production-oriented equipment are needed to disseminate industrial production of sugary kefir. The main challenges in the fermentation process are related to the contamination and transport of natural starter cultures. It is necessary to find a way to stabilize microbial growth, to ensure that the same microorganism groups are present in different environments and to standardize the quality. The historical development process from traditional yogurt production to modern yogurt production technologies will make significant contributions to the production of sugary kefir as well as milk kefir.

\section{Acknowledgements}

The authors gratefully acknowledge Mr. Ersan Borsan for providing translation assistance. This work was not supported by any institution or organization.

\section{Abbreviations}

- AAB: Acetic acid bacteria

- DPPH: 1,1-diphenyl-2-picrylhydrazyl

- IFN: Interferon

- IL: Interleukin

- LAB: Lactic acid bacteria

\section{References}

Alsayadi, M., Al Jawfi, Y., Belarbi, M., \& Sabri, F. Z. (2012). Antioxidant potency of water kefir. Journal of Microbiology, Biotechnology and Food Sciences, 2(6), 2444-2447.

Altunkaynak, B. Z., \& Özbek, E. (2006). Obezite: nedenleri ve tedavi seçenekleri. Van Tip Dergisi, 13(4), 138-142.

Ariza, M. T., Martinez-Ferri, E., Dominguez, P., Medina, J. J., Miranda, L., \& Soria, C. (2015). Effects of harvest time on functional compounds and fruit antioxidant capacity in ten strawberry cultivars. Journal of Berry Research, 5(2), 71-80. http://dx.doi.org/10.3233/JBR-150090.

Blaiotta, G., Di Capua, M., Romano, A., Coppola, R., \& Aponte, M. (2014). Optimization of water curing for the preservation of chestnuts (Castanea sativa Mill.) and evaluation of microbial dynamics during process. Food Microbiology, 42, 47-55. http://dx.doi.org/10.1016/j. fm.2014.02.009. PMid:24929716.
Borgeraas, H., Johnson, L. K., Skattebu, J., Hertel, J. K., \& Hjelmesaeth, J. (2018). Effects of probiotics on body weight, body mass index, fat mass and fat percentage in subjects with overweight or obesity: a systematic review and meta-analysis of randomized controlled trials. Obesity Reviews, 19(2), 219-232. http://dx.doi.org/10.1111/ obr.12626. PMid:29047207.

Chen, Y. T., Lin, Y. C., Lin, J. S., Yang, N. S., \& Chen, M. J. (2018). Sugary kefir strain lactobacillus mali APS1 ameliorated hepatic steatosis by regulation of SIRT-1/Nrf- 2 and gut microbiota in rats. Molecular Nutrition \& Food Research, 62(8), e1700903. http://dx.doi. org/10.1002/mnfr.201700903. PMid:29508520.

Corona, O., Randazzo, W., Miceli, A., Guarcello, R., Francesca, N., Erten, H., Moschetti, G., \& Settanni, L. (2016). Characterization of kefir-like beverages produced from vegetable juices. LebensmittelWissenschaft + Technologie, 66, 572-581. http://dx.doi.org/10.1016/j. lwt.2015.11.014.

Davidovic, S. Z., Miljkovic, M. G., Antonovic, D. G., Rajilic-Stojanovic, M. D., \& Dimitrijevic-Brankovic, S. I. (2015). Water Kefir grain as a source of potent dextran producing lactic acid bacteria. Hemijska Industrija, 69(6), 595-604. http://dx.doi.org/10.2298/ HEMIND140925083D.

de LeBlanc, A. d. M., Matar, C., Farnworth, E., \& Perdigon, G. J. C. (2006). Study of cytokines involved in the prevention of a murine experimental breast cancer by kefir. Cytokine, 34(1-2), 1-8. https:// doi.org/10.1016/j.cyto.2006.03.008.

Demirci, A. S., Palabiyik, I., Ozalp, S., \& Tirpanci Sivri, G. (2019). Effect of using kefir in the formulation of traditional Tarhana. Food Science and Technology (Campinas), 39(2), 358-364. http://dx.doi. org/10.1590/fst.29817.

Esmek, E. M., \& Güzeler, N. (2015). Kefir ve Kefir Kullanılarak Yapılan Bazı Ürünler. Harran Tarım ve Gida Bilimleri Dergisi, 19(4), 250-258.

Fiorda, F. A., Melo Pereira, G. V., Thomaz-Soccol, V., Medeiros, A. P., Rakshit, S. K., \& Soccol, C. R. (2016). Development of kefirbased probiotic beverages with DNA protection and antioxidant activities using soybean hydrolyzed extract, colostrum and honey. Lebensmittel-Wissenschaft + Technologie, 68, 690-697. http://dx.doi. org/10.1016/j.lwt.2016.01.003.

Fiorda, F. A., de Melo Pereira, G. V., Thomaz-Soccol, V., Rakshit, S. K., Pagnoncelli, M. G. B., Vandenberghe, L. P. S., \& Soccol, C. R. (2017). Microbiological, biochemical, and functional aspects of sugary kefir fermentation - A review. Food Microbiology, 66, 86-95. http://dx.doi. org/10.1016/j.fm.2017.04.004. PMid:28576377.

Gaware, V., Kotade, K., Dolas, R., Dhamak, K., Somwnshis, S., Nikam, V., \& Kashid, V. (2011). The magic of kefir: a review. Pharmacologyonline, 1, 376-386.

Ghazzay, M. H. (2014). Propagation of kefir in various sugar media. International Journal of Basic and Applied Sciences, 14, 41-45.

Golowczyc, M. A., Silva, J., Teixeira, P., De Antoni, G. L., \& Abraham, A. G. (2011). Cellular injuries of spray-dried Lactobacillus spp. isolated from kefir and their impact on probiotic properties. International Journal of Food Microbiology, 144(3), 556-560. http:// dx.doi.org/10.1016/j.ijfoodmicro.2010.11.005. PMid:21144610.

Gul, O., Atalar, I., Mortas, M., \& Dervisoglu, M. (2018). Rheological, textural, colour and sensorial properties of kefir produced with buffalo milk using kefir grains and starter culture: A comparison with cows' milk kefir. International Journal of Dairy Technology, 71, 73-80. http://dx.doi.org/10.1111/1471-0307.12503.

Gulitz, A., Stadie, J., Ehrmann, M., Ludwig, W., \& Vogel, R. F. (2013). Comparative phylobiomic analysis of the bacterial community of water kefir by $16 \mathrm{~S} r$ RNA gene amplicon sequencing and ARDRA 
analysis. Journal of Applied Microbiology, 114(4), 1082-1091. http:// dx.doi.org/10.1111/jam.12124. PMid:23289707.

Gulitz, A., Stadie, J., Wenning, M., Ehrmann, M. A., \& Vogel, R. F. (2011). The microbial diversity of water kefir. International Journal of Food Microbiology, 151(3), 284-288. http://dx.doi.org/10.1016/j. ijfoodmicro.2011.09.016. PMid:22000549.

Guzel-Seydim, Z. B., Kok-Tas, T., Greene, A. K., \& Seydim, A. C. (2011). Review: functional properties of kefir. Critical Reviews in Food Science and Nutrition, 51(3), 261-268. http://dx.doi. org/10.1080/10408390903579029. PMid:21390946.

Hill, C., Guarner, F., Reid, G., Gibson, G. R., Merenstein, D. J., Pot, B., Morelli, L., Canani, R. B., Flint, H. J., Salminen, S., Calder, P. C., \& Sanders, M. E. (2014). Expert consensus document. The International Scientific Association for Probiotics and Prebiotics consensus statement on the scope and appropriate use of the term probiotic. Nature Reviews. Gastroenterology \& Hepatology, 11(8), 506-514. http://dx.doi.org/10.1038/nrgastro.2014.66. PMid:24912386.

Hsieh, H. H., Wang, S. Y., Chen, T. L., Huang, Y. L., \& Chen, M. J. (2012). Effects of cow's and goat's milk as fermentation media on the microbial ecology of sugary kefir grains. International Journal of Food Microbiology, 157(1), 73-81. http://dx.doi.org/10.1016/j. ijfoodmicro.2012.04.014. PMid:22578996.

Huseini, H. F., Rahimzadeh, G., Fazeli, M. R., Mehrazma, M., \& Salehi, M. (2012). Evaluation of wound healing activities of kefir products. Burns, 38(5), 719-723. http://dx.doi.org/10.1016/j.burns.2011.12.005. PMid:22237053.

Kalicka, D., Znamirowska, A., Pawlos, M., Buniowska, M., \& Szajnar, K. (2019). Physical and sensory characteristics and probiotic survival in ice cream sweetened with various polyols. International Journal of Dairy Technology, 72(3), 456-465. http://dx.doi.org/10.1111/14710307.12605.

Karabulut, H., \& Gülay, M. Ş. (2016). Antioksidanlar. Mehmet Akif Ersoy Üniversitesi Veteriner Fakültesi Dergisi, 1(1), 65-76. http:// dx.doi.org/10.24880/maeuvfd.260790.

Kerry, R. G., Patra, J. K., Gouda, S., Park, Y., Shin, H. S., \& Das, G. (2018). Benefaction of probiotics for human health: a review. Yao Wu Shi Pin Fen Xi, 26(3), 927-939. http://dx.doi.org/10.1016/j. jfda.2018.01.002. PMid:29976412.

Kim, D. H., Chon, J. W., Kim, H., \& Seo, K. H. (2015). Modulation of intestinal microbiota in mice by kefir administration. Food Science and Biotechnology, 24(4), 1397-1403. http://dx.doi.org/10.1007/ s10068-015-0179-8.

Kim, D. H., Jeong, D., Kim, H., Kang, I.-B., Chon, J.-W., Song, K.-Y., \& Seo, K.-H. (2016). Antimicrobial activity of kefir against various food pathogens and spoilage bacteria. Han-gug Chugsan Sigpum Haghoeji, 36(6), 787-790. http://dx.doi.org/10.5851/kosfa.2016.36.6.787. PMid:28115890.

Kıvanç, M., \& Yapıcı, E. (2015). Kefir as a probiotic dairy beverage: determination lactic acid bacteria and yeast. International Journal of Food Engineering, 1, 55-60. http://dx.doi.org/10.18178/ijfe.1.1.55-60.

Kıvanç, M., \& Yapıc1, E. (2018). Survival of Escherichia coli O157:H7 and Staphylococcus aureus during the fermentation and storage of kefir. Food Science and Technology (Campinas), 39(Suppl. 1), 225230. http://dx.doi.org/10.1590/fst.39517.

Koh, W. Y., Utra, U., Ahmad, R., Rather, I. A., \& Park, Y. H. (2018). Evaluation of probiotic potential and anti-hyperglycemic properties of a novel Lactobacillus strain isolated from water kefir grains. Food Science and Biotechnology, 27(5), 1369-1376. http://dx.doi. org/10.1007/s10068-018-0360-y. PMid:30319846.
Laureys, D., \& De Vuyst, L. (2014). Microbial species diversity, community dynamics, and metabolite kinetics of water kefir fermentation. Applied and Environmental Microbiology, 80(8), 2564-2572. http:// dx.doi.org/10.1128/AEM.03978-13. PMid:24532061.

Laureys, D., Cnockaert, M., De Vuyst, L., \& Vandamme, P. (2016). Bifidobacterium aquikefiri sp. nov., isolated from water kefir. International Journal of Systematic and Evolutionary Microbiology, 66(3), 1281-1286. http://dx.doi.org/10.1099/ijsem.0.000877. PMid:26739269.

Leite, A. M., Miguel, M. A., Peixoto, R. S., Ruas-Madiedo, P., Paschoalin, V. M., Mayo, B., \& Delgado, S. (2015). Probiotic potential of selected lactic acid bacteria strains isolated from Brazilian kefir grains. Journal of Dairy Science, 98(6), 3622-3632. http://dx.doi.org/10.3168/ jds.2014-9265. PMid:25841972.

Leroi, F., \& Pidoux, M. (1993). Detection of interactions between yeasts and lactic-acid bacteria isolated from sugary kefir grains. The Journal of Applied Bacteriology, 74(1), 48-53. http://dx.doi. org/10.1111/j.1365-2672.1993.tb02995.x.

Maalouf, K., Baydoun, E., \& Rizk, S. (2011). Kefir induces cell-cycle arrest and apoptosis in HTLV-1-negative malignant T-lymphocytes. Cancer Management and Research, 3, 39-47. http://dx.doi.org/10.2147/ CMR.S15109. PMid:21448298.

Magalhaes, K. T., Pereira, G. D. M., Dias, D. R., \& Schwan, R. F. (2010). Microbial communities and chemical changes during fermentation of sugary Brazilian kefir. World Journal of Microbiology \& Biotechnology, 26(7), 1241-1250. http://dx.doi.org/10.1007/s11274-009-0294-x. PMid:24026929.

Magalhães-Guedes, K. T., Souza, U., Silva, M. R., Santos, F. L., \& Nunes, I. L. (2018). Production of rice cereal-based Kefir beverage. African Journal of Biotechnology, 17(10), 322-327. http://dx.doi.org/10.5897/ AJB2017.16362.

Marsh, A. J., O’Sullivan, O., Hill, C., Ross, R. P., \& Cotter, P. D. (2013). Sequence-based analysis of the microbial composition of water kefir from multiple sources. FEMS Microbiology Letters, 348(1), 79-85. http://dx.doi.org/10.1111/1574-6968.12248. PMid:24004255.

Miguel, M. G. C. P., Cardoso, P., Magalhães-Guedes, K. T., \& Schwan, R. F. (2011). Profile of microbial communities present in tibico (sugary kefir) grains from different Brazilian States. World Journal of Microbiology and Biotechnology, 27(8), 1875-1884. http://dx.doi. org/10.1007/s11274-010-0646-6.

Mironczuk-Chodakowska, I., Witkowska, A. M., \& Zujko, M. E. (2018). Endogenous non-enzymatic antioxidants in the human body. Advances in Medical Sciences, 63(1), 68-78. http://dx.doi. org/10.1016/j.advms.2017.05.005. PMid:28822266.

Morrissey, W. F., Davenport, B., Querol, A., \& Dobson, A. D. (2004). The role of indigenous yeasts in traditional Irish cider fermentations. Journal of Applied Microbiology, 97(3), 647-655. http://dx.doi. org/10.1111/j.1365-2672.2004.02354.x. PMid:15281947.

Nale, Z., Tontul, I., Aşçi Arslan, A., Sahin Nadeem, H., \& Kucukcetin, A. (2018). Microbial viability, physicochemical and sensory properties of kefir microcapsules prepared using maltodextrin/Arabic gum mixes. International Journal of Dairy Technology, 71(Supp. 1), 61-72. http://dx.doi.org/10.1111/1471-0307.12402.

Nualkaekul, S., \& Charalampopoulos, D. (2011). Survival of Lactobacillus plantarum in model solutions and fruit juices. International Journal of Food Microbiology, 146(2), 111-117. http://dx.doi.org/10.1016/j. ijfoodmicro.2011.01.040. PMid:21411170.

Pidoux, M. (1989). The microbial flora of sugary kefir grain (the gingerbeer plant): biosynthesis of the grain fromLactobacillus hilgardii producing a polysaccharide gelFlore microbienne du grain de kefir sucré (plant de la bière de gingembre): biosynthèse du grain 
par Lactobacillus hilgardii produisant un gel de polysaccharide. MIRCEN Journal of Applied Microbiology and Biotechnology, 5(2), 223-238. http://dx.doi.org/10.1007/BF01741847.

Puerari, C., Magalhaes, K. T., \& Schwan, R. F. (2012). New cocoa pulpbased kefir beverages: microbiological, chemical composition and sensory analysis. Food Research International, 48(2), 634-640. http:// dx.doi.org/10.1016/j.foodres.2012.06.005.

Randazzo, W., Corona, O., Guarcello, R., Francesca, N., Germana, M. A., Erten, H., \& Settanni, L. (2016). Development of new non-dairy beverages from Mediterranean fruit juices fermented with water kefir microorganisms. Food Microbiology, 54, 40-51. http://dx.doi. org/10.1016/j.fm.2015.10.018.

Rodrigues, K. L., Caputo, L. R., Carvalho, J. C., Evangelista, J., \& Schneedorf, J. M. (2005). Antimicrobial and healing activity of kefir and kefiran extract. International Journal of Antimicrobial Agents, 25(5), 404-408. http://dx.doi.org/10.1016/j.ijantimicag.2004.09.020. PMid:15848295.

Rosa, D. D., Dias, M. M. S., Grzeskowiak, L. M., Reis, S. A., Conceicao, L. L., \& Peluzio, M. (2017). Milk kefir: nutritional, microbiological and health benefits. Nutrition Research Reviews, 30(1), 82-96. http:// dx.doi.org/10.1017/S0954422416000275. PMid:28222814.

Rosa, D. D., Grzeskowiak, L. M., Ferreira, C. L., Fonseca, A. C., Reis, S. A., Dias, M. M., \& Peluzio Mdo, C. (2016). Kefir reduces insulin resistance and inflammatory cytokine expression in an animal model of metabolic syndrome. Food \& Function, 7(8), 3390-3401. http:// dx.doi.org/10.1039/C6FO00339G. PMid:27384318.

Saarela, M. (2018). Future development of probiotic dairy products. In A. Y. Tamime (Ed.), Probiotic dairy products (chap. 10, pp. 389-393). Hoboken: Wiley Blackwell.

Sharifi, M., Moridnia, A., Mortazavi, D., Salehi, M., Bagheri, M., \& Sheikhi, A. (2017). Kefir: a powerful probiotics with anticancer properties. Medical Oncology (Northwood, London, England), 34(11), 183. http://dx.doi.org/10.1007/s12032-017-1044-9. PMid:28956261.

Sikander, A. (2007). Kinetics of invertase production by Saccharomyces cerevisiae in batch culture. Pakistan Journal of Botany, 39(3), 907-912.

Silva, C. F. G. D., Santos, F. L., Santana, L. R. R. D., Silva, M. V. L., \& Conceicao, T. D. A. (2018a). Development and characterization of a soymilk Kefir-based functional beverage. Food Science and Technology (Campinas), 38(3), 543-550. http://dx.doi.org/10.1590/1678-457x.10617.

Silva, H. L. A., Balthazar, C. F., Silva, R., Vieira, A. H., Costa, R. G. B., Esmerino, E. A., Freitas, M. Q., \& Cruz, A. G. (2018b). Sodium reduction and flavor enhancer addition in probiotic prato cheese: contributions of quantitative descriptive analysis and temporal dominance of sensations for sensory profiling. Journal of Dairy Science, 101(10), 8837-8846. http://dx.doi.org/10.3168/jds.201814819. PMid:30077456.

Silva, K. R., Rodrigues, S. A., Xavier, L. Fo., \& Lima, A. S. (2009). Antimicrobial activity of broth fermented with kefir grains. Applied Biochemistry and Biotechnology, 152(2), 316-325. http://dx.doi. org/10.1007/s12010-008-8303-3. PMid:18663417.

Soares, M. B., Almada, C. N., Almada, C. N., Martinez, R. C. R., Pereira, E. P. R., Balthazar, C. F., Cruz, A. G., Ranadheera, C. S., \& Sant'Ana, A. S. (2019). Behavior of different Bacillus strains with claimed probiotic properties throughout processed cheese ("requeijão cremoso") manufacturing and storage. International Journal of Food Microbiology, 307, 108288. http://dx.doi.org/10.1016/j. ijfoodmicro.2019.108288. PMid:31421399.

Soccol, C. R., Vandenberghe, L. P. D., Spier, M. R., Medeiros, A. B. P., Yamaguishi, C. T., Lindner, J. D., \& Thomaz-Soccol, V. (2010). The potential of probiotics: a review. Food Technology and Biotechnology, 48(4), 413-434.

Tamang, J. P., Shin, D. H., Jung, S. J., \& Chae, S. W. (2016). Functional properties of microorganisms in fermented foods. Frontiers in Microbiology, 7, 578-590. http://dx.doi.org/10.3389/fmicb.2016.00578. PMid:27199913.

Teruya, K., Myojin-Maekawa, Y., Shimamoto, F., Watanabe, H., Nakamichi, N., Tokumaru, K., Tokumaru, S., \& Shirahata, S. (2013). Protective effects of the fermented milk Kefir on X-ray irradiation-induced intestinal damage in B6C3F1 mice. Biological \& Pharmaceutical Bulletin, 36(3), 352-359. http://dx.doi.org/10.1248/bpb.b12-00709. PMid:23229389.

Tomar, O. (2019). The effects of probiotic cultures on the organic acid content, texture profile and sensory attributes of Tulum cheese. International Journal of Dairy Technology, 72(2), 218-228. http:// dx.doi.org/10.1111/1471-0307.12574.

Tomar, O., Çağlar, A., \& Akarca, G. (2017). Kefir ve Sağlık Açısından Önemi. Afyon Kocatepe Üniversitesi Fen Ve Mühendislik Bilimleri Dergisi, 17(2), 834-853.

Topuz, E., Derin, D., Can, G., Kürklü, E., Çınar, S., Aykan, F., Çevikbaş, A., Dişçi, R., Durna, Z., Şakar, B., Saglam, S., Tanyeri, H., Deniz, G., Gürer, Ü., Taş, F., Guney, N., \& Aydıner, A. (2008). Effect of oral administration of kefir on serum proinflammatory cytokines on 5-FU induced oral mucositis in patients with colorectal cancer. Investigational New Drugs, 26(6), 567-572. http://dx.doi.org/10.1007/ s10637-008-9171-y. PMid:18762864.

Vinderola, C. G., Duarte, J., Thangavel, D., Perdigon, G., Farnworth, E., \& Matar, C. (2005). Immunomodulating capacity of kefir. The Journal of Dairy Research, 72(2), 195-202. http://dx.doi.org/10.1017/ S0022029905000828. PMid:15909685.

Ward, H. M. (1891). The 'Ginger-Beer Plant', and the organisms composing it: a contribution to the study of fermentation-yeasts and bacteria. Philosophical Transactions of the Royal Society of London, 50, 261-265.

Yildiz, F. (2016). Development and manufacture of yogurt and other functional dairy products. Hoboken: CRC press. http://dx.doi. org/10.1201/9781420082081.

Yönetmeliği, T. G. K. (2002). Türk Gida Kodeksi. TC Resmi Gazete., $23172,16$.

Zamberi, N. R., Abu, N., Mohamed, N. E., Nordin, N., Keong, Y. S., Beh, B. K., Zakaria, Z. A. B., Nik Abdul Rahman, N. M. A., \& Alitheen, N. B. (2016). The antimetastatic and antiangiogenesis effects of kefir water on murine breast cancer cells. Integrative Cancer Therapies, 15(4), 53-66. http://dx.doi.org/10.1177/1534735416642862. PMid:27230756.

Zanirati, D. F., Abatemarco, M. Jr., Sandes, S. H. D., Nicoli, J. R., Nunes, A. C., \& Neumann, E. (2015). Selection of lactic acid bacteria from Brazilian kefir grains for potential use as starter or probiotic cultures. Anaerobe, 32, 70-76. http://dx.doi.org/10.1016/j.anaerobe.2014.12.007. PMid:25542841. 